\title{
ENSURING AUDITOR INDEPENDENCE: THE CASE FOR SMALL AND MEDIUM PRACTICES IN MALAYSIA
}

\author{
NOR HAFIZAH ZAINAL ABIDIN 1 \\ SHERLIZA PUAT NELSON ${ }^{1}$ \\ MASLINA AHMAD1, *
}

Received: 28 November 2019 / Revised: 13 April 2020 / Accepted: 14 April 2020

Published online: 12 February 2021

(C) 2021 Faculty of Business and Accountancy, University of Malaya. All rights reserved.

\begin{abstract}
A B S T R A C T
Research aim: The study aims to examine small and medium audit firms' compliance with the independence requirements as stipulated in the International Standard on Quality Control 1 (ISQC 1) in Malaysia.

Design/ Methodology/ Approach: This study is qualitative in nature. It uses semi-structured interviews to gather input from 27 managers and partners of small and medium audit firms in Malaysia.
\end{abstract}

Research findings: The findings highlight variations in compliance practices on the independence requirements among small and medium audit firms. Some of the firms partially complied with the independence requirements, whereas others showed non-compliance. The findings further indicate that the majority documented their independence policies and procedures using an audit manual or audit checklist, communicated during the year. The study also found that the lack of financial and physical resources is considered the main hindrance to greater compliance.

Theoretical contribution/ Originality: There is a lack of research on the actual compliance with the independence requirements among small and medium firms in emerging economies. This study addressed that gap by focusing on small and medium audit firms in Malaysia. The majority of previous studies on regulatory inspection had focused on Anglo-Saxon countries. Practitioner/ Policy implication: The findings suggest that small and medium audit firms have done their best to comply with the independence requirements despite constraints on financial and human resources. As such, further awareness of the importance of independence would enhance the compliance level as well as audit value and the quality of firms.

Research limitation: Interview data were extracted from a small sample; hence, generalisation may need to be defined more cautiously when applied to other contexts. Moreover, since the respondents were selected based on their agreement, the findings reflecting their practices may not be applicable to other small and medium audit firms.

Keywords: Independence, Breach and Threat, Small and Medium Firms, Qualitative Research, Interview, ISQC 1

Type of article: Research paper

JEL Classification: M42, M480

${ }^{1}$ Kulliyyah of Economics and Management Sciences, International Islamic University Malaysia, Kuala Lumpur
53100, Malaysia. *email: maslina@iium.edu.my 


\section{Introduction}

Quality control on audit practices is governed by the International Standards on Quality Control 1 (ISQC 1) issued by the International Federation of Accountants (IFAC). The ISQC 1 stipulates six elements of a quality control system: leadership, ethical requirements, client relationships, human resources, engagement performance, and monitoring. This quality control system applies to the broad practices of firms in ensuring compliance with the professional standards and regulatory requirements of the profession. In this regard, audit firms are required to document evidence of their operations of each element of the quality control system. This evidence must be retained for an appropriate period of time for the purpose of future inspection. The main objectives of the ISQC 1 are to sustain audit quality and to contain audit failures since high compliance to the standard is perceived as high audit quality.

The Malaysian Institute of Accountants (MIA) has introduced the Practice Review Framework as one of the mechanisms to monitor auditors' compliance with the technical and ethical standards. It was introduced in 2003 pursuant to the requirement of the MIA By-Laws (Part II Section 550: Quality Assurance and Practice Review). The Practice Review Report issued in February 2014 disclosed that approximately 44 per cent of the audit firms that were audited (639 first time review out of 1362 registered audit firms) were categorised as follow-up review or Type 3 . Type 3 audit firms are firms with deficiencies. The report suggested that the majority of the key control objectives in the firms had not been maintained. These deficiencies were likely to materially affect the overall quality of an audit engagement (MIA, 2014, p. 8). The results of the second review conducted on the Type 3 cases indicated that 50 per cent of such cases had improved on their audit quality and passed the practice review, whereas the balance failed the review and would be referred to the Investigation Committee.

Subsequently, in a recent Practice Review Report issued in 2018, 56 reports had been finalised (MIA, 2018). High-risk audit firms were selected using the risk-based approach, which generally excludes audit firms registered with the Audit Oversight Board (AOB). Based on the 56 finalised reports, 38 firms were categorised into Type 3, of which 24 would require a remedial action plan (RAP) while another 14 were referred for disciplinary action. Meanwhile, two audit firms were categorised into Type 4 and referred for disciplinary action. The Type 4 category is the latest category added to the revised Practice Review Framework. This category includes firms that breach the requirements and may eventually result in the revocation of licence. Meanwhile, the Type 3 category currently focuses on monitoring review with proper action plans through corrective actions involving root cause analysis and preventive measures rather than a follow-up review as practised previously. 
These Practice Reviews revealed inadequacies in the implementation of the ISQC 1 among the audit firms in Malaysia. It was further disclosed that several sole-proprietorship firms had mistakenly assumed that the ISQC 1 did not apply to them due to their small firm size. As a result, these firms undermined themselves by preparing their own policies and procedures of the quality control system as well as the governance practices (MIA, 2014). In light of these outcomes, the current study is motivated to examine the challenges faced by small audit firms in realising the requirements of the ISQC 1 standard. In particular, the current study focuses on the independence requirements due to the pivotal role of independence in contributing to audit quality. Hence, first, this study aims to investigate how small and medium audit firms or better known as small and medium practices (SMPs) in Malaysia complied with the independence requirement policies and procedures of the ISQC 1 in particular. Second, this study also intends to gather the challenges faced by SMPs in complying with the independence requirements of the ISQC 1.

The common findings revealed by the Practice Review Report 2009-2013 indicated that no formal policies and procedures on professional requirements had been established by the sample audit firms (MIA, 2014). Further, there was little academic evidence that could highlight any detailed results of the inspection process of these SMPs (Chang et al., 2017). Therefore, the main objective of this study is to focus on SMPs and the process of their establishment of and compliance with the policies and procedures on relevant ethical requirements, specifically the independence requirements stipulated in Para 21 to 25 of the ISQC 1 . Para 21 to 25 specifically state the following: (i) Audit firms shall establish and communicate the policies and procedures on their independence requirements, (ii) the policies and procedures shall be reviewed and updated frequently, (iii) policies and procedures shall be established on appropriate actions to be taken in case of threats or breaches to the independence requirements, and (iv) in order to safeguard the familiarity threat, the procedure for partner rotation or quality control review shall also be in place.

This study contributes to the literature in several ways. First, this study is based on an Asian context where the audit practices differ substantially from the Anglo-Saxon context (i.e., the US audit market), which had been the focus of prior studies (Bedard et al., 2008; Church \& Shefchik, 2012; Vanstraelen \& Zou, 2020). A study involving an emerging economy would extend the research scope by highlighting the impacts of different regulatory requirements on compliance practices. Second, prior research (DeFond, 2010; DeFond \& Lennox, 2011; Knechel, 2013) had predominantly examined the impact of regulatory changes on perceived auditor's independence, besides investigating the effectiveness of self-regulation against independent regulation. Little research had been conducted on regulatory issues and their actual implementations. 
This study explores the practical reality of how the independence requirements were adopted and implemented by the SMPs in Malaysia. This study highlights the impact of regulation on the actual implementation of the independence requirements. Third, prior research was predominantly quantitative in nature (see Ismail et al., 2007; Kleinman, Lin, \& Palmon, 2014). Since this study uses qualitatively derived data, it provides in-depth and rich information on the topics discussed by the respondents. These findings provide an inward perspective of the respondents regarding the practical reality of implementing the independence requirements of the ISQC 1.

The remainder of this paper is structured as follows. Section 2 outlines the literature review, Section 3 explains the methodology, Section 4 discusses the findings, and Section 5 concludes the paper.

\section{Literature Review and Hypothesis Development}

\subsection{Regulation and Oversight Mechanisms in Malaysia}

In the past decade, Malaysia has seen a tremendous change in the regulation set up for the auditing profession, and audit firms have been reminded not to neglect the standards on quality control. This control was introduced as part of the regulation to strengthen the quality assurance programme for all audit firms. The oversight mechanism in Malaysia has evolved over the years from self-regulation to external regulation. The mission of external regulation is to improve audit quality and to protect the interests of investors. An assessment of the audit quality of audit firms would ensure that audit practices are systematic and effective as well as the regulatory requirements of the ISQC1 have been complied with.

In Malaysia, oversight mechanisms are under the purview of the MIA and AOB. While the MIA executes the oversight of SMPs, the oversight of auditors of public listed entities is done by the AOB. Specifically, Section 6 of the Accountants Act 1967 mandated the MIA as the regulatory body for the accountancy profession in Malaysia. Pursuant to Part II Section 550: Quality Assurance \& Practice Review of the MIA By-Laws (on Professional Conduct and Ethics), the Practice Review programme was first established in January 2003 and then revised in July 2017. The aim is to carry out surveillance activities on audit firms registered with the MIA to ensure that audit practitioners are adhering to the international standards as well as legal and regulatory requirements in performing their audit work and carrying out the policies and procedures of audit firms (MIA, 2014, p. 10). Meanwhile, the AOB is established under Part IIIA of the Securities Commission Act Malaysia 1993 which came into force on 1 April 2010. Likewise, the intention is to promote confidence in the quality and reliability of audited financial statements in Malaysia. The AOB is responsible for overseeing auditors of public interest entities or schedule 
funds and also foreign auditors who audit the financial statements of foreign listed entities on Bursa Malaysia.

The Practice Review is meant to safeguard the auditing practices and policies by ensuring that audit firms meet the required standards so as to reduce substandard performance. Corrective actions are recommended following this independent Practice Review. It appears that auditing the auditors is now the driving force for continuously improving the profession (Hassan \& Naser, 2013). Despite this being the case, the acceptance rate of the Practice Review still seems to be still low (Ismail et al., 2007).

As mentioned earlier, the Practice Review Report issued in 2018 had disclosed that a number of firms did not comply with the requirements of the ISQC 1, particularly among the SMPs which seemed to be lacking in appropriate policies and procedures on the quality control system, as well as governance practices (MIA, 2018). This disclosure confirmed the findings noted in the Practice Review Report 2009-2013, which mentioned that formal policies and procedures on independence requirements were still far from being established (MIA, 2014). Findings of the Practice Review Report issued in 2018 also highlighted the failure of practitioners or partners to inculcate a culture of quality in the firm. As observed in the Practice Review findings, significant deficiencies reflected the failure of leadership to inculcate good communication, directive, actions, and behaviours.

\subsection{Regulatory Inspection in Developed Countries}

Auditor independence has been a subject of rigorous debate for many years due to major corporate collapses and perceived audit failures. The discussion has mainly centred on threats on auditor independence, and audit quality (Tepalagul \& Lin, 2014; Kleinman et al., 2014). Past scandals had also prompted the introduction of more stringent regulations for audit firms and auditors' practices, particularly on the independence requirements. In the US, the Public Company Audit Oversight Board (PCAOB) was introduced to strengthen the reigns on the regulation of audit firms (Church \& Shefchik, 2012; DeFond, 2010). An inspection process was developed to enhance and benefit the audit quality (Church \& Shefchik, 2012). This process identifies the nature and severity of deficiencies noted in the audit quality as well as any recurring audit deficiencies, and their implications on audit quality. These deficiencies highlight the inadequacies of the auditing and accounting standards, documentation, or testing.

The oversight mechanisms used in the US audit markets have evolved over the years, shifting from self-regulation to government regulation, i.e., PCAOB. Regardless of industry or context, a high-quality audit is necessary. This is more so in a well-functioning capital market where audit litigations are prevalent and auditor reputations are extremely vulnerable (Defond, 2010). While the 
PCAOB inspects public company audits, peer reviews are largely confined to the audits of private companies, which seem to be a necessary measure. The PCAOB's inspections have brought in many benefits. For instance, Aobdia and Shroff (2017) found that the PCAOB's inspection of non-US auditors had enhanced their reputation by means of increasing the market share from 4 per cent to 6 per cent. In a similar vein, the regulatory scrutiny has also increased the assurance value of the inspection; it has highlighted the importance of public regulatory oversight over the audit market. This was observed by Vanstraelen and Zou (2020), who found that audit inspections impacted the reputation of audit firms.

Literature (see Carlin et al., 2009; Choi et al., 2010) continues to support the proposition that the audit quality of large firms exceeds that of smaller firms, often attributed to their respective resources (Beatty, 1989). It seems inevitable as the audit inspections of small audit firms continue to reveal their unacceptable level of deficiencies (Kleinman et al., 2014). Consequently, lowquality auditors are subjected to greater scrutiny and harsher penalties. A previous study by Bedard et al. (2008) also found that small audit firms were more likely to violate reporting standards, with some even reported of having issues with the auditor-client's independent relationship.

Audit inspections cost money. The need for audit firms to comply with the PCAOB requirements increases the audit firm's operation cost, which tends to be passed on to the clients in the form of auditing fees. The additional cost of stricter compliance increases the small auditors' likelihood of losing their clients. Consequently, they become less competitive and may exit from the audit market (DeFond \& Lennox, 2011).

Although audit inspections help to enhance the audit quality of firms leading to significant changes in audit firms' behaviour (Vanstraelen \& Zou, 2020), the assessment of auditor independence needs to focus more at the individual office level rather than the entire firm level (Wallman, 1996; Francis, 2004). This is because practices at the national office may differ from those at the local audit offices while audit quality also tends to vary across different engagement offices, even within an audit firm. Further, most audit decisions for each client are made within each individual office. These suggest that officelevel characteristics play an important role in determining audit quality (Bedard et al., 2008).

\subsection{Self-regulation in Malaysia}

The audit market in Malaysia is identified as an oligopolistic market (Nor \& Abidin, 2015) because 60 per cent to 75 per cent of the market is controlled by the Big Four audit firms. At present, the Big Four audit firms focus on large clients due to their large resources. This scenario reduces the market share for 
the small and medium firms, which get only a small portion of the market share.

Prior studies (see Sanusi et al., 2008; Ismail et al., 2008) found a minimal implementation of the ISQC 1 by the majority of small and medium audit firms. Many also used non-standardised operating procedures that did not reflect total compliance. Ismail et al. (2007) stated that this practice was largely influenced by firms' attitude towards the perceived usefulness of the programme, as well as the rule of observant behaviour in complying with any regulation imposed on the accounting profession. Moreover, small auditors would incur a proportionally higher cost when stringently adhering to the higher standards imposed by the ISQC 1 (Omar et al., 2013). In this regard, small- and medium-sized audit firms are also constrained by other obstacles such as limited resources for updating, a lack of awareness for training, and a lack of understanding of the importance of the requirements imposed.

The audit quality offered by smaller firms has often been perceived to be low compared to that of bigger firms. This is inevitable since firm practices vary across different offices. While the non-standardisation of audits as practised by smaller firms may affect the audit quality of the respective audit firms, it cannot be assumed that smaller firms offer inferior services due to this practice. Smaller firms also offer their own procedures which may not be deemed as standardised. While the Big Four international audit firms have all the privilege to adhere to the requirements imposed, smaller firms are hindered by their low capital, size, and resources. Big audit firms can easily comply by implementing the needed requirements despite the costs, whereas smaller firms may find it a hindrance to do so. The objective of adhering to the financial reporting standards is to achieve the maximum possible harmony and minimum possible variations in practice among the reporting entities (Carlin et al., 2009).

Nonetheless, preceding literature has not been able to disclose how these audit firms comply with or implement the ISQC 1 , specifically those pertaining to the independence requirements. It is important to highlight that the mainstream literature on auditor independence has been biased to large entities and big audit firms. Little has been found to involve small and medium firms, especially those from the emerging economies. This study contributes to the growing audit literature by looking at the impact of regulation and the actual implementation of the independence requirements among small and medium audit firms in Malaysia.

\subsection{Agency Theory}

The separation of ownership from management results in a conflict of interest or agency problem that leads to the need for monitoring mechanisms (Jensen \& Meckling, 1976). The agency problem is a cost to the company and is mostly addressed by external auditors as part of the external monitoring mechanisms 
in corporate governance. External audit exists to monitor management activities and to attest to management's performance. The audit function is to provide feedback to shareholders via the board of directors based on the auditing process. Hence, to promote greater audit quality, external auditors have to uphold a high level of independence criteria. This notion is supported by Culpan and Trussel (2005), who emphasised that the auditors must be independent of the company and its management. This means that the auditors must be free from any conflict of interest. Without that independence, the auditors would have no role to play within the agency theory and their service would be of little or no value. External audits would induce truthful reporting and information to various stakeholders such as bankers, bondholders, investment analysts, the government, and others.

\section{Methodology}

Hypothetically, all audit firms are required to comply with the requirements of the ISQC 1. It is noted that the Big Four audit firms and those registered with the Audit Oversight Board (AOB) have practically complied with the ISQC 1 requirements. Sanusi et al. (2018) also observed that auditors are bound by the movement from the International Federation of Accountants (IFAC) in their effort to improve the quality of the audit service they provide to clients. However, Omar and Mohd. Alwi (2007) found evidence of limited implementation of the ISQC 1 among small and medium audit firms. Small and medium audit firms were suggested to have been operating based on nonstandard operating procedures, which might not truly reflect their compliance with the ISQC 1.

Therefore, in light of this evidence, small and medium audit firms were selected for the current study. This is also consistent with the findings of the MIA Practice Review Report 2009-2013 (MIA, 2014), which mentioned that these firms were lacking in their compliance with the ISQC 1 requirements. Concomitant to this, partners and/or managers would be the most appropriate candidates to be interviewed on the information related to compliance with the ISQC 1 requirements since they are the decision makers involved with the adoption and implementation of the requirements imposed by the regulatory authorities.

To gain an in-depth understanding of the subject matter, this study used semi-structured interviews to gather input from 27 respondents from small and medium audit firms in Malaysia. They were partners or managers of these audit firms. The initial effort to identify these SMPs had involved 130 inquiries made to the small and medium firms available in Kuala Lumpur and Selangor. The list of all audit firms in Malaysia was obtained from the MIA. From these enquiries, only 27 respondents or representatives agreed to be interviewed, and a verbal request was made before the interview. In total, the interview process 
took about five months, involving the 27 audit firms located within urban and sub-urban areas of Kuala Lumpur. This is consistent with Sanusi et al. (2018), who documented this central area as representing 70 per cent of Malaysia's audit market.

Qualified enumerators were engaged to conduct the interviews at the respective audit firms of the respondents. The enumerators were briefed prior to the interviews to focus on the respondents' perceptions of the nature of policies in place and the extent of compliance with the said requirements. The interview sessions varied in length from 40 minutes to two hours. Consent was asked for the interviews to be recorded. However, two interviews were carried out without any recording due to the request of the interviewees. Handwritten notes were used in this context. Interviews were conducted until data redundancy had occurred in the following interviews and reached the saturation level.

The questions posed to the interviewees focused on the policies and procedures applied by them on the issue of breach and threat towards the independence requirements. The information gathered from the face-to-face interview sessions was recorded and transferred to the word processor and then transcribed. The same was done for the hand-recorded interviews. The participants were coded for anonymity. The data were read and re-read for emerging themes and concepts. These were then matched to the categories as prescribed by the interview questions. Data were analysed based on the withincase and cross-case approach. These were then summarised, and the pattern coded (Hubberman \& Miles, 1994). For the coding process, documents such as firms' checklist, policies and procedures were also reviewed. Pattern coding is a way of grouping summaries into a smaller number of sets, themes, or constructs. This method was applied due to its ability to reorganise and condense the vast array of initial analytic details from the interviews into the main output.

\section{Results}

Based on the main research questions, this study examines "how" the actual compliance with the independence requirements is being implemented within the SMPs, as well as the challenges confronted by them throughout the compliance practices. Results of the analysis on the actual implementation practices are aligned to the requirements stipulated within the ISQC 1 and prior literature, resulting in three important themes. Hence, this study's findings on the SMPs' practical compliance with the independence requirements are grouped into three themes, namely: (1) establishment and communication of the independent requirements, (2) policies and procedures on threats and breaches to the independence requirements, and (3) partner rotation. 


\subsection{Establishment and Communication of Independence Requirements}

The interview data revealed that half of the audit firms had established written policies on the independence requirements, as required by the ISQC 1 . These policies were documented in the form of an audit manual and/or audit checklist. The documents were continuously made available to the employees as part of their reference. This practice would assist the firms in instilling awareness among the existing and new employees. Excerpts of the interviews are provided in support of this finding.

"We do document the ISQC requirements in our quality control manuals.... and normally we communicate these to staff during our training that were carried out twice a year." (AF6)

"...normally there is a compilation of forms to be filled by the engagement team prior to any commencement of an audit. This is often completed by the manager in charge of the audit engagement." (AF23)

"Every team member is supposed to sign the checklist before commencement on the job and filed in the audit file." (AF10)

Regarding the effort to formally document the independence requirements and raise awareness among staff, some firms did so in an informal manner. No proper procedure was documented; instead, it was done mainly through verbal communications as and when needed.

"We create awareness among the staff through brief verbal communication normally at the entry point... however, we don't have any particular return or form to fill up or even procedures in written... and we rarely update the issue, only once a while..." (AF13)

One partner argued that the general knowledge about independence should be common knowledge that everyone in accounting should know. This is because the independence topic is taught during undergraduate studies.

"This is supposed to be common knowledge. Everyone should know all these things and we don't have to remind them every day." (AF10)

The findings also indicate that the policies and procedures in some firms were communicated and disseminated to all staff within the firm, albeit only from time to time. Similarly, the information on the independence requirements was often disseminated to staff during meetings, training, and induction courses. Any change made to the independence requirements as 
circulated by the MIA would also be highlighted similarly or as and when deemed necessary.

"We have in-house trainings. At least twice a year...so that's where we will emphasise the independence requirements to the staff." (AF27)

Periodically, firms need to obtain a written representation from all the staff for more effective monitoring of compliance with the independence requirements. Most of the firms showed their level of compliance with the ISQC 1 requirements by implementing the independence declaration. This finding is consistent with Amirul et al. (2015), who found that firms do have policies and procedures in place for their teams to comply with the applicable legal and regulatory requirement.

As such, a written independence declaration was obtained from all the professional personnel on an annual basis. Some firms took the liberty of ensuring that the professional staff had filled up the independence declaration form upon joining the firm. Further, at the engagement level, some firms also took steps to ensure that the manager in charge filled up the independence declaration form before the commencement of every engagement. This practice was to ensure that the clients, the firm, and the employees did not have any conflict of interest with the engagement.

“...before we hire someone... they will need to fill the independence declaration form. Then, all the audit jobs will need to have its independence declaration. This is to ensure that, even the staff are also independent from the client." (AF27)

"Normally after the completion of an engagement, we will go through the filing and check whether any compliance matters are complied with. This is examined by the manager in charge." (AF23)

"For example, we have independence questionnaires form that is compulsory to be filled for every audit engagement regardless if it is with an old or new client." (AF16)

In the case where there is a network of associates of audit firms, this study found that some of the headquarters $(\mathrm{HQ})$ or main offices would observe and monitor this practice throughout all the offices. The interviews revealed that the practices of the small and medium firms' offices or branches might differ from those of the main office, which could be due to different management styles practised by the partners. A similar finding was also noted by Bedard et al. (2008). 
"...every year we will visit and compare documentation and practices in other offices. Our HQ is very strict about the quality." (AF9)

Interestingly, the current study also documented an audit firm that had a permanent staff supervising the technical and auditing matters, which is a normal practice among big audit firms. The aim was to ensure that the audit firm complied with all the requirements and standards set by the authority.

"...we have a Technical Director. And as the Technical Director, she will ensure that all are complied to. She will also get herself updated with the latest changes within MIA... she will send out memo to all staff by email." (AF27)

In summary, the extent to which SMPs complied with the independence requirements of the ISQC 1 was through their own practices. It was noted that firms that observed strong compliance would establish formal documentation of the independence requirements. At the firm level, the documentation of the independence requirements was included in the audit manual, which would be used as a general practice in the audit firm. Meanwhile, at the engagement level, an audit checklist was used to ensure compliance with the independence requirements. Concomitant to that, for an individual employee, an independence declaration was required, either annually or at the beginning of every engagement. In short, the implementation of standard procedures on the independence requirements of the ISQC 1 was seen to be implemented formally at firm, engagement, and individual levels. As such, the independence requirements seemed to be consistently emphasised within the workplace and audit engagements throughout the year.

In terms of communicating the independence requirements, the levels of implementation were found to be varied among the SMPs. Any change announced by the respective authority would be constantly updated via emails or other modes of communication to employees. It was observed that some SMPs complied with the requirements in an informal manner. Therefore, the results reflect their medium or lower level of implementation in relation to the independence requirements. Hence, the findings of the current study show that the levels of implementation and communication of the independence requirements varied across the SMPs. The findings also highlight that these firms faced some constraints in complying with the ISQC 1 requirements, as discussed in the subsequent section.

\subsection{Policies and Procedures on Threats and Breaches to Independence Requirements}

Regarding the procedures on threats and breaches to the independence requirements, it was found that most of the interviewed firms did not have any 
proper policies or procedures to address specific threats to professional independence. In some firms, the policies and procedures for threats identification were included in the firms' quality assurance manual. Under normal circumstances, firms assess the threats prior to the commencement of an audit engagement. Two possible threats may need to be considered - threats at the employee level and threats on the audit client-firm relationship. Threats at the employee level refer to the presence of an employee that has a conflict of interest with the potential client; for instance, an employee has a significant number of shares in the said clients. Meanwhile, threats on the audit client-firm relationship refer to threats that exist due to a long-term relationship between the parties or significant amounts owed by a client to the audit firm. Thus, firms would assess and review the extent and nature of these threats; they would also evaluate the impact of these threats on the independence of the client-firm relationship, if any, as stated by the following respondents.

"We don't specifically have SOP, however, we do have observation and reviews on the independence in every team...team members know who is who..." (AF10)

"Normally we examine in the process of allocating the audit job...if the staff has relationship with the client or not...but so far, we never encounter those issues..." (AF8)

In the case of a confirmed threat imposed by an employee (such as the employee has a significant interest in the client), the affected staff would be removed from the engagement team or replaced. However, in some cases, the affected staff may be retained because his/her presence would not affect the decision making of the audit process, depending on the severity of the threat. For instance, if the affected staff was only a junior level staff, he/she would most likely not be involved in any decision making in the audit engagement. The senior audit team member needs to be aware of the scenario and inform the management. Most of the time, the management of the audit firm would request this issue to be highlighted promptly, even if the engagement team was in the midst of audit fieldwork. The preceding facts were highlighted by several partners.

“...assessment of threats often done prior to the start of any engagement..."

"We normally measure the extent of conflict of interest. For instance, if they are relative but not affecting decision making or give any big impact, then the staff would still involve in the assignment." (AF23) 
"That's why if there are any problems, we will advise our staff to inform us promptly. Even if they have something to discuss during the fieldwork." (AF16)

These control mechanisms in managing the threats to independence confirm the findings of Beasley et al. (2001), who mentioned the increasing likelihood of detecting related-party transactions. The partners of the firm would assess the relationship between the counterparty and the client or its management, and even the audit staff, before making any decision or taking any action.

Some small and medium firms would also consider the impacts of any potential breach or threat to independence. Based on the findings of this study, it was noted that some of the SMPs perceived that their audit firms would not be affected by such a breach of independence. Many of these firms believed that the impact would not be significant because most of their clients were private companies. Hence, the impact of any breach or threat to independence would be very minimal. The situation is different for public interest entities, which are likely to be impacted significantly and financially due to the wider scope of the stakeholders. This is exemplified by the Enron/Andersen scandal in 2001, where the negative stock returns demonstrated how significant the impact was for a public listed entity (Numata \& Takeda, 2010). The following comments were recorded from the respondents of this study.

"Breach of independence will never happen to us. In fact, our clients are mostly private limited companies, and they do not have complicated transactions or relationships...more importantly those relationships would unlikely influence any decisions or judgement to our audit..." (AF13)

"Every year we would assess the independence requirements particularly large companies that exist among our clients' portfolio, so it's quite frequent that we did that..." (AF12)

"...our clients are mostly not from large companies, most of them are from the small and medium enterprise companies only." (AF9)

Since the clientele of these SMPs mainly consisted of small and medium enterprises, the audit firms did not expect any occurrence of a breach of independence. Hence, these firms hardly developed any specific procedures for the possibility of a breach of independence.

"...at the moment we hardly have any breach, and we also don't have any proper procedures in place. Management will decide how to handle if there is any." (AF10) 
Even if there were any policies or procedures prepared, as stated by a partner (AF23), a kind of assessment on these threats would be conducted prior to the engagement. If any evidence was found regarding a staff member's involvement in a breach, either he/she would be removed from the team or the client would be rejected. Hence, the findings of this study suggest that SMPs would prefer to take preventive measures rather than take any risk of facing punishments. Considering their limited resources, any form of corrective action would be costly and time consuming. Thus, prevention would be better than cure.

The SMPs were not only periodically assessing their own firm's compliance with the independence requirements but also regularly supervising their review process to enhance the extent of this compliance. For this purpose, firms' performance on compliance was reviewed at both individual and engagement levels. For this to be efficient, a checklist is crucial. The current study found that some firms assigned a specific coordinator to oversee the compliance matters. The firms involved had a discipline unit or technical director to monitor and evaluate the staff's awareness of the said compliance. Technically, this coordinator would convey any updates or changes relevant to the firm via staff meetings, training, or email.

“...we also check details of directors and shareholders during the statutory audit. By doing so, we could reduce the threats to independence... and normally we will reject the audit if we foresee that there is a possibility of breach of independence. Even if it occurred in the middle of the audit engagement. However, most of the time we really try hard to avoid high-risk client." (AF16)

The current study observed that the SMPs regularly practised early identification and detection, performed through the annual independence declaration and at the start of an audit engagement. This practice implies that the SMPs were fully aware of the independence requirement.

In short, the findings indicate that despite the absence of standard policies and procedures, the assessments of threats or breaches of independence are being complied with in the routines of an audit engagement. As such, issues of threats or breaches, if any, are handled on a case-by-case basis.

\subsection{Partner Rotation}

The ISQC 1 was developed to minimise threats to independence, and one of its recommendations is partner rotation. This is because a longer relationship or association would eventually increase familiarity threats that may affect the basis of the judgement and create a conflict of interest. This study observed that the majority of the firms' practising partner also applied the partner rotation basis. However, only SMPs serving clients from the government or other 
statutory bodies would strictly observe this recommendation. In addition, only the entities registered under or bound by the Cooperative Acts were required to limit the auditors' term for a maximum of six years. The current study noted that even if the partner rotation requirement was adhered to by the audit firms, the practice only involved the partners from within the firm, and the rotation often ranged from between three and five years, as evidenced in the following excerpt.

“...partner in charge is being rotated every five years... however, on yearly basis, the manager portfolio will be reviewed. And the job will be rotated once in every three or four years." (AF23)

"Partner rotation is compulsory for government entities or any related statutory bodies and the duration is normally for five years." (AF12)

Tackett et al. (2004) highlighted that the four-year time period of audit rotation required by the PCAOB is semi-arbitrary. There may be some resistance from the public accounting firms who have had the same audit clients for many years. However, the findings of the current study revealed no such resistance but more of the failure to comply. The partner rotation requirement was not observed due to the limited number of partners available. Inadvertently, it also occurred among the firms' branches and associates. It was noted that the rotation was based on the availability of partners as well as partners' current workloads and responsibilities. Existing literature suggests that heavy workloads would result in less audit effort per audit engagement, thereby lowering audit quality. This would trigger a higher likelihood of audit deficiencies in the client's audit engagement, which could be due to insufficient audit procedures causing failures to detect the client's departure from the Generally Accepted Accounting Practices (Chang et al., 2017). Several respondents of the current study had expressed their concerns on this issue.

"...then how to rotate if the firm only has one partner. But our main office will go to each of our associate office and make sure their work complies to the standards." (AF9)

"...allocation of clients would depend on the partner's availability...we tried searching from other offices and if we can find any available partner." (AF8)

In a nutshell, the findings of this study revealed that the partners in SMPs were aware of their limited resources to rotate, and they tried their best to comply with the standards. Further, the practice of partner rotation was also strongly influenced by the client's profile. For instance, if the client was from a 
government or statutory body category, the engagement was known to be strictly monitored by the National Audit Department. Therefore, the firms would abide accordingly.

\subsection{Challenges}

The findings of this study revealed a number of challenges that SMPs encountered in their effort to comply with the independence requirements imposed by the ISQC 1 .

\subsubsection{Financial and Physical Resources}

First and foremost, the SMPs lacked the needed resources to implement this requirement of the ISQC 1 successfully. It is estimated that in Malaysia, many SMPs are still lagging in the ISQC 1 even though the regulation had been in place since 2006 (MIA, 2014). The next challenge encountered by the SMPs is their lack of physical resources and human capital. These SMPs were struggling with constraints caused by their limited resources and high staff turnover rate. Offering non-competitive salaries in the market had restrained their capability to recruit and retain well-deserving staff. The majority of the partners also explicitly commented on how they had trouble collecting their fees from clients due to bureaucratic challenges.

"...our cash flow is very tight, since clients also have issues with their cash flows. So, in other way, it also badly affected our collection of fees. Therefore, we have to limit our resources, staff and funds...in the end, people just want to survive...it's not easy to get our collection. Sometimes the governance practices were a little bit too much to adhere to also..." (AF13)

\subsubsection{Information Gap and High Costs Incurred}

Challenges in resources were not the only issues faced by the SMPs. The information gap that existed between their clients and the International Standard on Auditing (ISA) requirements also compounded the situation. If documentations were not prepared according to the standards, there would be significant consequences later on, imposed by the authority. In this study, the majority of the respondents highlighted the constraints they faced. They commented that the compliance exercise would require a greater time allocation, and staff would need time to prepare these documentations appropriately. Hypothetically, the length of time taken to prepare such documentation would depend on the requirements imposed. As is prevalent in all industries, time is money. Therefore, the higher the time consumed, the higher the cost incurred. The high compliance cost, the limited number of staff, 
and financial constraints had indirectly caused the SMPs to carefully align themselves on their compliance with the independence requirements.

Prior studies (see Omar et al., 2013; Choi et al., 2010) had demonstrated that small auditors are likely to incur a proportionally higher cost, in line with the stringent compliance with higher standards required under the ISQC 1. Choi et al. (2010) also documented that large offices or large firms have a cost advantage in producing audit services of similar quality; thus, they are able to charge lower billing rates as compared to small offices.

Arguably, the chance of survival in the market is more significant than "complying". The allocation of the financial resources of these SMPs is an important issue as it concerns their survival in the competitive auditing market, as highlighted by a partner.

“...to survive in this industry it's always about money i.e. fund collection...the firm is managing between staffing, hours spent on the job, profit margin etc...so it's about delivering the services first...quality is difficult to measure as the reporting is just about commissioning to the template..." (AF13)

\subsubsection{Perception of Auditing Values}

Based on the evidence obtained from the current study, there appear to be some differences in audit firms' perception of the intrinsic values of an audit. In this regard, auditing was perceived merely as a compliance exercise; thus, it was not the firms' topmost priority. As mentioned earlier, the aim of the ISQC 1 requirements is to uphold the integrity of audit firms and enhance the quality of financial reporting. As highlighted by Kleinman et al. (2014), the choice of standards is to shape auditors' behaviour with clients on the reality of the clients' financial and internal control systems. In addition, it is also to ensure that clients comply with the financial accounting standards. To achieve these goals, SMPs have to invest more time, which would inadvertently incur higher costs for them. In this regard, the SMPs need to strategise appropriately.

Apart from having to subscribe to all the requirements imposed by the ISQC 1, SMPs also have to compete with bigger firms for business within an emerging market, and this can be exceptionally challenging. Add to this is the low capital of SMPs as compared to bigger firms. This situation not only curtails their ability to adhere to the requirements but also limits their capacity to hire capable employees who can bring benefits to their firms, such as those wellversed in compliance issues as well as competitive partners for the rotation purposes. Disadvantaged at both ends, it appears that impairment on the independence requirements by SMPs is inevitable. Consequently, it may also weaken the quality of financial reporting. 


\section{Conclusion}

The current study examined how SMPs implemented and complied with the independence requirements of the ISQC 1 and the challenges they faced in implementing those requirements. Data were collected through semistructured interviews from 27 SMPs, and the results of the analysis based on prior literature and the ISQC 1 revealed three main themes. These three themes are: (1) establishment and communication of the independence requirements, (2) policies and procedures on threats and breaches to the independence requirements, and (3) partner rotation.

First, the findings on the establishment and implementation of the independence requirements revealed variations in the SMPs' practices in complying with the independence requirements. These variations include formal and informal compliance, full or partial compliance, or no compliance at all. For instance, the results of the study show that in the case of formal and full compliance, the audit firm would document the standard policies and procedures in their audit manual or quality assurance manual to maintain common practices throughout the audit firm, while an audit checklist would be used for assessments in an audit engagement. In terms of communication, it is done upon any changes made by the regulatory authority. Hence, the findings of mixed practices of implementation are consistent with prior literature (see Kleinman et al., 2014; Sanusi et al., 2008; Ismail et al., 2007), which found different levels of compliance among firms. The findings regarding efficient monitoring and frequent checking on firms' practices as noted in the current study to ensure good quality services are also in line with the findings of Aobdia and Shroff (2017).

Regarding the second and third themes, the results of this study indicate the presence of policies and procedures on threats and breaches of independence in the quality assurance manual. The impact of threats or breaches to the firm or a particular audit engagement was assessed prior to any decision making by the audit firms. Finally, most SMPs would adhere to a specific requirement made by the relevant authority regarding partner rotation. Other than that, partner rotation would usually happen among the existing partners within the current networks or associates.

The SMPs confronted several challenges in complying with the independence requirements of the ISQC 1 . Nonetheless, the sample SMPs in this study made their best effort to comply with the independence requirements even though faced with financial and employment challenges. This outcome was also verified by Omar et al. (2013), who found staffing and financial resources a challenge for audit firms. They also mentioned that updating and complying with all the independence requirements was another difficulty faced by smaller audit firms. This study also uncovered that compliance practices could be influenced by the impact of breaches or threats 
on clients' stakeholders. This interesting finding is supported by DeFond and Lennox (2011), who mentioned that small and medium firms tended to be more careful in handling clients that had a larger impact on their stakeholders. Moreover, Ismail et al. (2007) revealed that small and medium firms faced constraints in managing their limited and valued resources. In the context of this study, it was detected that the firms involved were of the view that minimum compliance would be better than not complying at all. For these SMPs, it was a matter of survival and sustaining their business since they were disadvantaged by their lack of financial resources.

Finally, this study documented that a small number of the SMPs that were still in practice did not fully comply with the regulatory requirements of the ISQC 1. Based on the discovery in this study, it is suggested that regulatory bodies, particularly the MIA, oversee the establishment of allies or associate firms as they share similar resources with several other firms. In addition, monitoring the risk-based assessment on compliance behaviour among the partners of small and medium firms, prior to the renewal of the license, would be one measure to strengthen the independence requirements awareness and its importance. This study also recommends that small and medium firms form their own alliance or merger in order to remain competitive and to be able to pool their resources as a way of cutting down high expenses.

This study experienced limitations in the form of the small sample size used. In this regard, generalisation to the rest of the audit market has to be delicately defined. It is recommended that future research explore the influence of leadership style on compliance practices within audit firms. Future studies may also examine partners' business mindset when confronted with client and firm practices.

\section{Acknowledgment}

The authors would like to thank the Ministry of Education of Malaysia for the Fundamental Research Grant Scheme (FRGS) awarded for this research.

\section{References}

Amirul, S. M., Md. Salleh, M. F., \& Abu Bakar, M. A. (2015). Audit firm governance: An overview from Malaysia. Procedia Economics and Finance, 31, 632-639. https://doi.org/10.1016/S2212-5671(15)01151-X

Aobdia, D., \& Shroff, N. (2017). Regulatory oversight and auditor market share. Journal of Accounting and Economics. 63(2-3), 262-287. https://doi.org/10.1016/j.jacceco.2017.03.001

Beasley, M. S., Carcello, J. V., \& Hermanson, D. R. (2001). Top 10 audit deficiencies. Journal of Accountancy, 191(4), 63-66. https://www.journalofaccountancy.com/issues/2001/apr/top10auditdeficiencies.html

Beatty, R.P. (1989). Auditor reputation and the pricing of initial public offerings. Accounting Review, 64(4), 693-709. https:// doi.org/10.1016/S1061-9518(96)90008-7 
Bedard, J. C., Deis, D. R., Curtis, M. B., \& Jenkins, J. G. (2008). Risk monitoring and control in audit firms: A research synthesis. Auditing: A Journal of Practice and Theory, 27(1), 187-218. https://doi.org/10.2308/aud.2008.27.1.187

Carlin, T. M., Nigel, F., \& Laili, N. H. (2009). Investigating audit quality among Big 4 Malaysian firms. Asian Review of Accounting, 17(2), 96-114. https:// doi.org/10.1108/13217340910975251

Chang, C. J., Luo, Y., \& Zhou, L. (2017). Audit deficiency and auditor workload: evidence from PCAOB triennially inspected firms. Review of Accounting and Finance, 16(4), 478-496. https:// doi.org/10.1108/RAF-03-2017-0050

Choi, J. H., Kim, C., Kim, J. B., \& Zang, Y. (2010). Audit office size, audit quality, and audit pricing. Auditing: A Journal of Practice and Theory, 29(1), 73-97. https://doi.org/10.2308/aud.2010.29.1.73

Church, B. K., \& Shefchik, L. B. (2012). PCAOB inspections and large accounting firms. Accounting Horizons, 26(1), 43-63. https://doi.org/10.2308/acch-50077

Culpan, R., \& Trussel, J. (2005). Applying the agency and stakeholder theories to the Enron debacle: an ethical perspective. Business and Society Review, 110(1), 59-76. https://doi.org/10.1111/j.0045-3609.2005.00004.x

DeFond, M. L. (2010). How should the auditors be audited? Comparing the PCAOB inspections with the AICPA peer reviews. Journal of Accounting and Economics, 49(1-2), 104108. https:// doi.org/10.1016/j.jacceco.2009.04.003

DeFond, M. L., \& Lennox, C. S. (2011). The effect of SOX on small auditor exits and audit quality. Journal of Accounting and Economics, 52(1), 21-40. https://doi.org/10.1016/j.jacceco.2011.03.002

Francis, J. R. (2004). What do we know about audit quality? The British Accounting Review, 36(4), 345-368. https://doi.org/10.1016/j.bar.2004.09.003

Hassan, Y. M., \& Naser, K. (2013). Determinants of audit fees: Evidence from an emerging economy. International Business Research, 2(3), 56-74. https://doi.org/10.5539/ibr.v6n8p13

Hubberman, A. M., \& Miles, M. B. (1994). Qualitative data analysis. London, England: Sage Publications.

Ismail, A. H., Mohd-Sanusi, Z., \& Isa, Y. (2008, Dec). Implementation of audit quality control system: preliminary evidence from small and medium audit practices in Malaysia. Paper presented at the $9^{\text {th }}$ Asian Academic Accounting Association Annual Conference, Dubai, United Arab Emirates.

Ismail, S., Haron, H., Ismail, I., \& Vinten, G. (2007). Factors influencing auditors' acceptance of the practice review system. Asian Academy of Management Journal, 12(2), 57-82. http://web.usm.my/aamj/12.2.2007/AAMJ\%2012-2-4.pdf

Jensen, M. C., \& Meckling, W. H. (1976). Theory of the firm: managerial behavior, agency costs and ownership structure. Journal of Financial Economics, 3(4), 305-360. https://doi.org/10.1016/0304-405X(76)90026-X

Kleinman, G., Lin, B. B., \& Palmon, D. (2014). Audit quality: A cross-national comparison of audit regulatory regimes. Journal of Accounting, Auditing and Finance, 29(1), 61-87. https://doi.org/10.1177\%2F0148558X13516127

Knechel, W. R. (2013). Audit quality and regulation. International Journal of Auditing, 20 (3), 215-223. https://doi.org/10.1111/ijau.12077

Malaysian Institute of Accountants (MIA) (2014). Practice Review Report 2009-2013. Retrieved from

https://www.mia.org.my/v2/downloads/resources/publications/surveillance/practic e/2009/MIA_Practice_Review_Report_2009_2013.pdf

Malaysian Institute of Accountants (MIA) (2018). The audit profession in Malaysia 2018. Retrieved

from 
https://www.mia.org.my/v2/downloads/resources/publications/surveillance/practic e/2018/MIA_The_Audit_Profession_2018.pdf

Nor, M. N. M., \& Abidin, S. (2015). The structure of Malaysian audit market: from 2008 to 2010. Paper presented at the $3^{\text {rd }}$ IBEA International Conference on Business, Economics and Accounting, Vietnam.

Numata, S., \& Takeda, F. (2010). Stock market reactions to audit failure in Japan: The case of Kanebo and ChuoAoyama. The International Journal of Accounting, 45(2), 175-199. https://doi.org/10.1016/j.intacc.2010.04.004

Omar, N., \& Mohd Alwi, M. J. (2007). International standard on quality control (ISQC 1): a survey report for the Malaysian Institute of Accountants (MIA). Working paper, Universiti Teknologi MARA, Selangor.

Omar, N., Sanusi, Z. M., Yaacob, N. A. \& Mohamed, S. (2013, May). Audit quality assessment on an audit firm: compliance and challenges. Paper presented at the $5^{\text {th }}$ International Conference on Financial Criminology, Selangor, Malaysia.

Sanusi, Z. M., Iskandar, T. M., Monroe, G. S., \& Saleh, N. M. (2018). Effects of goal orientation, self-efficacy and task complexity on the audit judgement performance of Malaysian auditors. Accounting, Auditing and Accountability Journal, 31(1), 75-95. https:// doi.org/10.1108/AAAJ-12-2015-2362

Sanusi, Z. M., Ismail, A. H., Isa, Y. M., Tapsir, R., Kasim, S., Muhamad, K., Chantrathevi, T., \& Zaini, N. (2008, August). Audit quality control: development of self-assessment checklist for small and medium audit practices in Malaysia. Paper presented at the International Accounting and Business Conference, Johor Baru, Malaysia.

Tackett, J., Wolf, F., \& Claypool, G. (2004). Sarbanes-Oxley and audit failure: A critical examination. Managerial Auditing Journal, 19(3), 340-350. https://doi.org/10.1108/02686900410524355

Tepalagul, N., \& Lin, L. (2014). Auditor independence and audit quality: A literature review. Journal of Accounting, Auditing and Finance, 30(1), 101-121. https://doi.org/10.1177\%2F0148558X14544505

Vanstraelen, A., \& Zou, L. (2020). PCAOB Inspections and Audit Fees: An Analysis of Inspection Rounds of Small Audit Firms. European Accounting Review, 1-32. https://doi.org/10.1080/09638180.2020.1828121

Wallman, S. M. (1996). The future of accounting, part III: Reliability and auditor independence. Accounting Horizons, 10(4), 76-97. 